\title{
A Rare Case of Isolated Agenesis of the Thyroid Isthmus: Surgical Implications
}

\author{
Gaurang Singhal ${ }^{1}$ Pradeepti Nayak ${ }^{1}$ Nishi Sharma ${ }^{1}$ \\ 1 Department of ENT, Atal Bihari Vajpayee Institute of Medical \\ Sciences, Dr. Ram Manohar Lohia Hospital, Delhi, India \\ Int J Recent Surg Med Sci 2023;9:56-58. \\ Address for correspondence Pradeepti Nayak, MBBS MS, Department \\ of ENT, Atal Bihari Vajpayee Institute of Medical Sciences, Dr. Ram \\ Manohar, Lohia Hospital, Baba Kharak Singh Marg, Connaught Place, \\ Delhi 110001, India (e-mail: pradeepti.nayak@gmail.com).
}

\begin{abstract}
The thyroid gland is the largest endocrine gland in the body and pathologies related to this gland are a fairly common occurrence in clinical practice. Various developmental abnormalities can distort the morphology of the thyroid gland. Variations in anatomy

Keywords

- agenesis

- isthmus

- thyroid may have critical clinical implications, both in terms of manifestations and surgical complications. In this report, we discuss a rare case of isolated agenesis of the thyroid isthmus that was discovered incidentally during the right thyroid lobectomy of a female patient who was diagnosed as the case of colloid goiter.
\end{abstract}

\section{Introduction}

Thyroid gland is the first endocrine gland to develop in an embryo. It develops by fusion of one median and two lateral anlagen. It weighs $\sim 15$ to $25 \mathrm{~g}$. It is $\sim 5^{*} 3^{*} 1.5 \mathrm{~cm}$ in size. An isthmus connects both lobes of the thyroid gland and lies against the second to fourth tracheal rings. The anomalies of development of the thyroid gland alter the morphology of the gland and may cause clinical and functional disorders. ${ }^{1}$ Various developmental anomalies of the thyroid gland have been reported such as ectopic thyroid, thyroglossal cyst or fistula, and persistent pyramidal lobe. However, the most uncommon anomalies include agenesis or hemi-agenesis of thyroid lobe and agenesis of isthmus. ${ }^{2}$ Agenesis of isthmus may be associated with absence of thyroid lobe or presence of ectopic thyroid tissue. However, agenesis of isthmus alone is extremely rare. Incidence of agenesis of isthmus has been reported to vary from 5 to $10 \%{ }^{3}$ This condition does not usually cause any clinical manifestations by itself and the diagnosis is usually incidental in the course of investigations in the presence of other thyroid pathology or during cadaveric dissections. ${ }^{4}$

article published online February 7, 2022
DOI https://doi.org/ 10.1055/s-0041-1741561. ISSN 2455-7420.

\section{Case Report}

A 50-year-old female presented to the Department of Otorhinolaryngology with the complaint of a swelling over the anterior aspect of neck for 10 years with no other symptoms. There was no history of any relevant surgical intervention. There was no history of features or symptoms suggestive of hypothyroidism or hyperthyroidism. On physical examination, there was a $3 * 2 \mathrm{~cm}$ swelling present in the right lobe of thyroid. No scars were seen over the neck. Patient was euthyroid and fine-needle aspiration cytology showed colloid goiter with cystic degeneration. Ultrasonography revealed a heterogeneously echoic nodule of $2^{*} 1.8 \mathrm{~cm}$ in the right lobe of the thyroid gland. She was planned for a right hemithyroidectomy after taking a written and informed consent, with appropriate preanesthetic clearance. During surgery, on retracting the strap muscles however, we directly reached the bare trachea ( $\mathbf{- F i g . 1}$ ). The isthmus could not be located despite adequate exploration. As the isthmus was absent, exploration was also conducted for ectopic thyroid tissue but none was found. The specimen was sent for histopathological examination and the report

\footnotetext{
(c) 2022. Medical and Surgical Update Society. All rights reserved. This is an open access article published by Thieme under the terms of the Creative Commons Attribution-NonDerivative-NonCommercial-License, permitting copying and reproduction so long as the original work is given appropriate credit. Contents may not be used for commercial purposes, or adapted, remixed, transformed or built upon. (https://creativecommons.org/ licenses/by-nc-nd/4.0/) Thieme Medical and Scientific Publishers Pvt. Ltd., A-12, 2nd Floor, Sector 2, Noida-201301 UP, India
} 


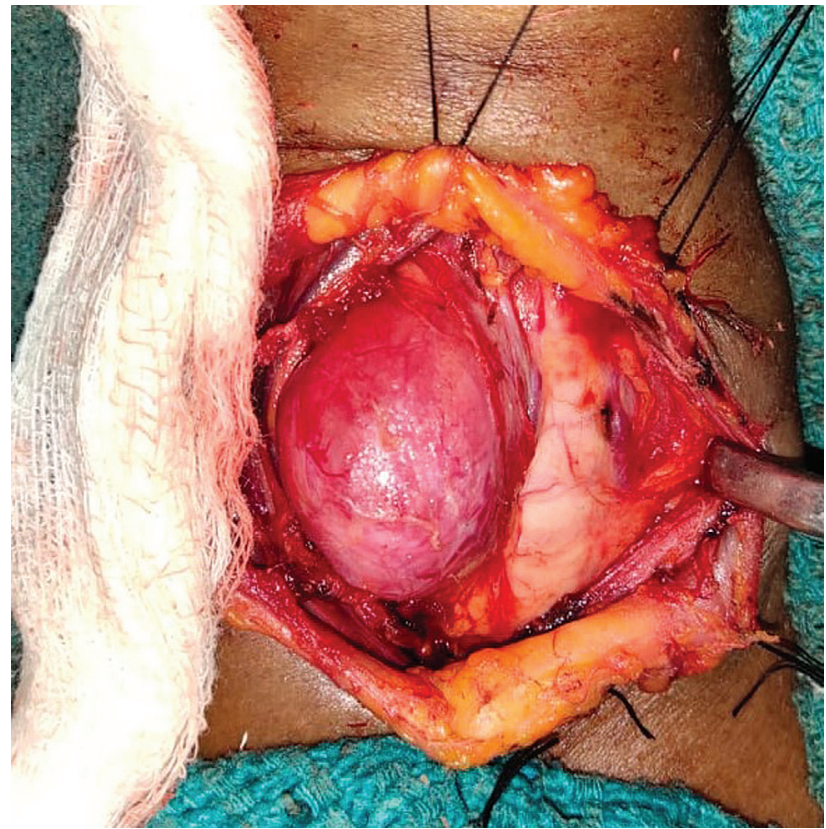

Fig. 1 Intraoperative photograph showing the bare trachea.

showed adenomatous goiter with focal areas of sclerosis. The postoperative period was uneventful (-Fig. 2).

\section{Discussion}

Agenesis of the thyroid isthmus is a developmental anomaly and is defined as the complete and congenital absence of the thyroid isthmus. ${ }^{3}$ Absence of isthmus was first reported in 1952 by Allan in 2 to $4 \%$ cases. $^{5}$ Anson reported absence of isthmus in 6 to $8 \%$ cases. $^{6}$

Embryologically the median anlage develops from ventral surface of primitive pharynx between the first and second pharyngeal arch, whereas the lateral anlagen develop from the fourth and fifth pharyngeal pouches. Lateral anlagen fuse with

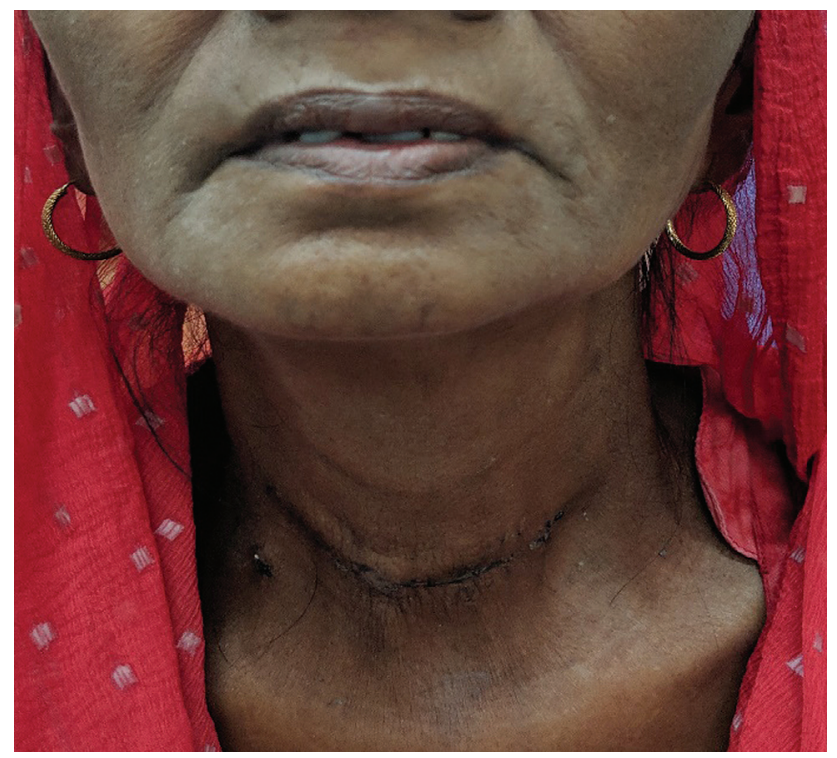

the median anlage by sixth week of gestation. A diverticulum then forms at the foramen cecum at 16 to 17 weeks of gestation that extends distally to form a bilobed structure. This structure is pulled by the descent of heart in front of the hyoid bone, pharyngeal cartilages, and the pharyngeal gut to rest at its final position. This diverticulum becomes a solid cellular cord called thyroglossal duct. It has been postulated that if the thyroglossal duct divides at the higher level it may generate thyroid lobes with an absent isthmus. ${ }^{7}$

De Felice and Di Lauro and Vassart and Dumont reported that mutations in the developmental genes TITF1, PAX8, FOXE1/TITF2 may result in agenesis of thyroid isthmus, especially TITF2, as this gene is essential for the development of palate and thyroid gland. ${ }^{8,9}$ Chromosome 22 also plays an important role in the development of the thyroid gland. ${ }^{10}$

Methods routinely employed to evaluate thyroid pathology including ultrasonography, computed tomography, magnetic resonance imaging, and scintigraphy may reveal this condition. In some cases, as in ours, it may be an incidental finding intraoperatively.

This rare embryological variance may have significant clinical implications. If the diagnosis of an absent thyroid isthmus is made, we should anticipate other embryological anomalies of the thyroid gland or the surrounding structures that have related phylogenetic development. Also, embryological variations should raise the suspicion of syndromic conditions that may involve the thyroid gland. In cases of thyroid isthmus agenesis, differential diagnoses of autonomous thyroid nodule, thyroiditis, primary carcinoma, neoplastic metastasis, and amyloidosis should be ruled out too. An absent thyroid isthmus may also have major surgical implications. There may be associated anatomical variations in vasculature, nerve supply, or even the morphology of the lobes and meticulous and cautious dissection is imperative to prevent injuries to vital structures during surgery. In cases where the surgery is being performed for thyroid malignancies and the isthmus is found to be absent, it is essential to explore thoroughly for the presence of ectopic thyroid tissue or other anomalies like a persistent pyramidal lobe or levator glandulae thyroideae to ensure adequate clearance.

\section{Conclusion}

In conclusion, dissection of the thyroid gland must be undertaken with utmost diligence and a thorough understanding of the anatomy of the gland to prevent any major or critical intra-operative or postoperative complication. Though rare, agenesis of the isthmus of the thyroid gland may be one of the congenital anomalies one may encounter during the surgery.

Funding

None.

Conflict of Interest

None declared.

Fig. 2 Postoperative photograph of the patient. 
58 Thyroid Isthmus Agenesis Singhal et al.

\section{References}

1 Jain A, Pathak S. Rare developmental abnormalities of thyroid gland, especially multiple ectopia: a review and our experience. Indian J Nucl Med 2010;25(04):143-146

2 Sankar KD, Bhanu PS, Susan PJ, Gajendra K. Agenesis of isthmus of thyroid gland with levator glandulae thyoidea. Int J Anat Var 2009; 2:29-30

3 Pastor VJ, Gil VJ, De Paz Fernandez FJ, Cachorro MB. Agenesis of the thyroid isthmus. Eur J Anat 2006;10:83-84

4 Melnick JC, Stemkowski PE. Thyroid hemiagenesis (hockey stick sign): a review of the world literature and a report of four cases. J Clin Endocrinol Metab 1981;52(02):247-251

5 Kumar A, Banarjee A, Harikrishan V. Case report: a congenital anomaly of thyroid gland with agenesis of isthmus and presence of pyramidal lobe. J Evol Med Dent Sci 2013;2:7899-7903
6 Marshall CF. Variations in the form of the thyroid gland in man. J Anat Physiol 1895;29(Pt 2):234-239

7 De Felice M, Di Lauro R. Thyroid development and its disorders: genetics and molecular mechanisms. Endocr Rev 2004;25(05): 722-746

8 Vassart G, Dumont JE. Thyroid dysgenesis: multigenic or epigenetic ... or both? Endocrinology 2005;146(12):5035-5037

9 Gangbo E, Lacombe D, Alberti EM, Taine L, Saura R, Carles D. Trisomy 22 with thyroid isthmus agenesis and absent gall bladder. Genet Couns 2004;15(03):311-315

10 Ozkan OF, Asık M, Toman H, Ozkul F, Cıkman O, Karaayvaz M. Agenesis of isthmus of the thyroid gland in a patient with gravesbasedow disease and a solitary nodule. Case Rep Surg 2013; 2013:608481. Doi: 10.1155/2013/608481 